\title{
Medical Product Stability
}

National Cancer Institute

\section{Source}

National Cancer Institute. Medical Product Stability. NCI Thesaurus. Code C70853.

The ability of a product to retain its properties within specified limits throughout its shelf life and to resist conditions that may affect its stated performance. The chemical, physical and microbiological aspects of stability are to be considered for a medical product according to 21 CFR Part 211 GMP. 